\title{
Structural characterization and thermally stimulated discharge conductivity (TSDC) study in polymer thin films
}

\author{
V S SANGAWAR, R J DHOKNE*, A U UBALE, P S CHIKHALIKAR and \\ S D MESHRAM ${ }^{\dagger}$ \\ PG Department of Physics, Govt. Vidarbha Institute of Science and Humanities, Amravati 444 604, India \\ ${ }^{\dagger}$ R.D.I.K. College, Badnera 444 701, India
}

MS received 24 July 2006; revised 18 September 2006

\begin{abstract}
The electrical conductivity of naphthalene doped polystyrene (PS) films $(\approx 61.58 \mu \mathrm{m}$ thick) was studied as a function of dopant concentration and temperature. The formation of charge transfer (CT) complexes and strong concentration dependence of carrier mobility point out that the current carriers are transported through doped polymer system via hopping among sites associated with the dopant molecules. The activation energy, $E_{\text {a }}$, was calculated from the graph of $\log \sigma \mathrm{vs} 10^{3} / T$ plot within low and high temperature regions.
\end{abstract}

Keywords. TSDC; PS; naphthalene; thermo-electrets; glass transition temperature $\left(T_{\mathrm{g}}\right)$.

\section{Introduction}

Recently, considerable amount of work has been reported on steady-state electrical conduction in insulating polymeric films. The work reported earlier emphasizes on different interpretations for the observed results but it seems no ultimate view has yet been reached. The elucidation of the underlying charge injection and carrier migration process is vital to the future utility of these materials.

It has been shown that carrier mobility can be greatly affected by impregnating the polymers with suitable dopants. The charge storage property of polymers can be considerably modified with the help of suitable dopants.

The conductivity of PS was studied (Ranjit Singh and Datt 1980) at constant polarizing field but at a different polarizing temperature. Sangawar and Adgaonkar (1995) reported that conductivity of PS increases with concentration of benzoic acid. Polymer composites based on charge transfer complex of phenothiazine and iodine with polystyrene prepared in different weight ratios have been characterized by FTIR, XRD, mechanical, microstructure and electrical properties (d.c. as well as a.c.) by Singh et al (2005)

Polystyrene, which is normally a poor electrical conductor, is chosen as a basic material for the present study. It forms charge transfer complex with suitable acceptors such as iodine (Chakraborthy et al 1991) and acrylic acid (Sinha and Srivastava 1979) by donating electrons to the acceptor molecules. The purpose of the present work is to carry out a careful study of steady state conduction of poly-

*Author for correspondence (raginidhokne@yahoo.co.in) styrene (PS) thin film thermo-electrets sandwiched between metal electrodes both in doped and undoped forms.

\section{Experimental}

\subsection{Sample preparation}

Polystyrene supplied by Polymer Chemical Industry, Mumbai and naphthalene by S.G. Sisco Pvt Ltd., New Delhi, were used for the study. Belsare and Deogaonkar (1998) prepared thin films by using isothermal evaporation technique and it is best suited to the laboratory condition. A similar procedure was adopted in the present case for the preparation of naphthalene doped PS samples. PS was dissolved in cyclohexanone (AR grade, supplied by $\mathrm{E}$ Merck India Ltd, Mumbai), then it was kept at $323 \mathrm{~K}$ in a temperature controlled muffle furnace for $12 \mathrm{~h}$ to obtain a homogenous solution. Then naphthalene was added to the homogenous solution of PS in different weight \% (5$30 \%$ ). Thin films were prepared by pouring the solution on a cleaned optically plane glass plate which was kept over a pool of mercury for perfect levelling so as to ensure uniform thickness. The whole system was allowed to evaporate at room temperature in dust free chamber and after complete evaporation the film was detached from the glass surface.

\subsection{Thickness measurement}

The thickness of sample was measured by the compound microscope in conjunction with an occoulometer having a least count of $15.38 \mu \mathrm{m}$, similar to the method reported by 
Mehendru and Chand (1983). The thickness of all samples was kept constant and is of the order of $\approx 61.58 \mu \mathrm{m}$.

\subsection{Electrode coating}

The electrode coating on the film of measured thickness was done by using quick drying and highly conducting silver paste supplied by Eltecks Corporation, Banglore. A mask of a circular aperture of $2.5 \mathrm{~cm}$ diameter was used while coating, to ensure uniformity in the size of the coated silver electrode.

\subsection{Structural characterization}

For structural characterization the X-ray diffractograms of undoped PS and naphthalene doped PS films were obtained on XRD-PKL 1729 Phillips Bulk XRD (Pune University, Pune) as shown in figure 1 . The X-ray diffractograms of all the samples were obtained to ascertain the amorphous or crystalline nature. The presence of naphthalene in PS thin film was confirmed by IR spectra of the sample taken on FTIR-8400 Spectrophotometer.

\subsection{Measurement of thermally stimulated discharge conductivity}

2.5a Electret preparation: Electroded sample was sandwiched between two brass electrodes of the sample holder. The metal polymer metal (M-P-M) system so formed was placed inside the furnace. The M-P-M system was heated at a nearly uniform rate up to a polarizing temperature, $T_{\mathrm{p}}=343 \mathrm{~K}$ and was maintained at that constant temperature for $30 \mathrm{~min}$. Different polarizing fields, $\left(E_{\mathrm{P}}\right), 3 \mathrm{kV} / \mathrm{cm}$, $5 \mathrm{kV} / \mathrm{cm}, 10 \mathrm{kV} / \mathrm{cm}, 15 \mathrm{kV} / \mathrm{cm}$ were applied using a stabilized d.c. voltage source for $1 \mathrm{~h}$ keeping the field ON.

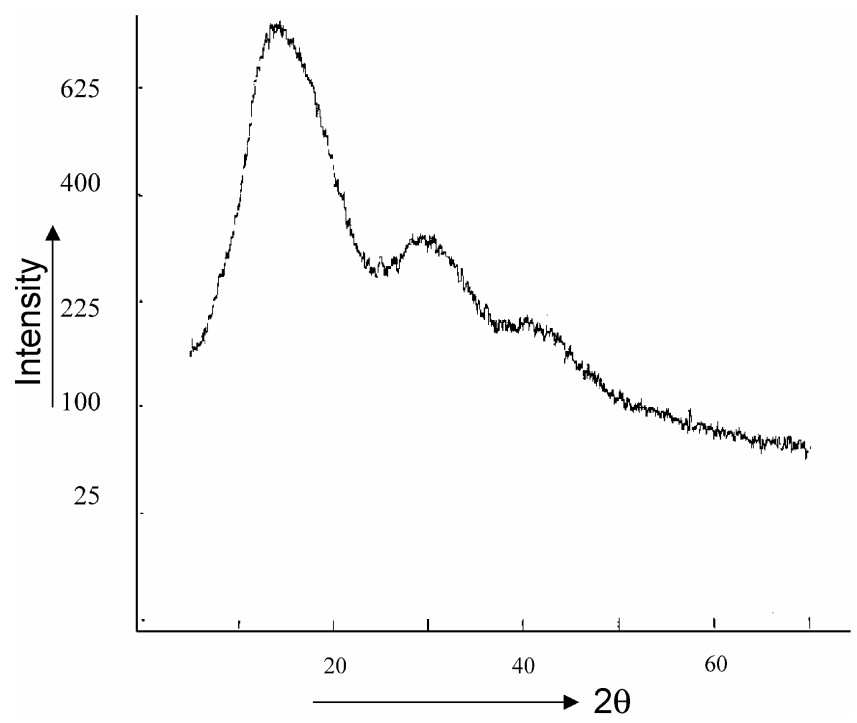

Figure 1. X-ray diffraction spectra of polymer samples.
The sample was slowly cooled to room temperature under continuing electric stress. Total time of polarization was adjusted to be $2.5 \mathrm{~h}$ in each case. After polarization, the field was removed and the sample was short circuited for $20 \mathrm{~min}$ in order to remove stored charges, if any. The electrets were prepared at different polarizing fields. A similar procedure was adopted for electret preparation as reported earlier by Burghate et al (2003).

2.5b Thermally stimulated discharge current: After the electret formation, the $\mathrm{M}-\mathrm{P}-\mathrm{M}$ assembly was placed in a controlled temperature furnace supplied by Pushpa Scientific, Hyderabad. The sample was short circuited through a sensitive picoammeter (Model DPA III Scientific Equipment, Roorkee, having an accuracy of $\pm 1 \mathrm{pA}$ ) for measurement of discharge current. The sample was thermally discharged at a uniform rate of $2 \mathrm{~K} / \mathrm{min}$ from $313-403 \mathrm{~K}$. The method used for conductivity measurement was the same as that reported earlier (Belsare and Deogaonkar 1998).

\section{Results and discussion}

The present study on polarizing field and temperature dependence of electrical conduction in undoped and doped films of PS has been carried out to understand the role of dopant when added in varying concentrations to a polymer matrix. In the present study, naphthalene is a dopant, doped in different weight $\%(5 \%, 10 \%, 20 \%, 30 \%)$ in PS. But results on only two concentrations $(5 \%, 30 \%)$ are discussed in detail because they show a remarkable effect on conduction of PS.

Figure 2 shows the thermally stimulated discharge conductivity (TSDC) thermograms $\left(\log \sigma \mathrm{vs} 10^{3} / T \mathrm{~K}^{-1}\right.$ plot) for undoped PS and naphthalene doped PS thermo-electrets at various polarizing fields $(3 \mathrm{kV} / \mathrm{cm}, 5 \mathrm{kV} / \mathrm{cm}, 10 \mathrm{kV} / \mathrm{cm}$, $15 \mathrm{kV} / \mathrm{cm})$.

Figure 2a shows TSDC thermograms of undoped PS for same polarizing field. PS is known to have a good charge storage capability owing to the presence of phenyl group. Figures $2 \mathrm{~b}$ and $\mathrm{c}$ show TSDC thermograms for naphthalene doped PS (5\% and 30\%, respectively) thermoelectrets for the same polarizing fields as in the case of undoped PS samples.

It is observed that d.c. conductivity of undoped PS has been enhanced by dopant (naphthalene) even if it is in lower concentration. But as the concentration increases, conductivity increases and it reaches to maximum value for higher concentration of dopant i.e. 30\% naphthalene in PS. An attempt was made to prepare PS film loaded with naphthalene concentration, $>30 \%$, but in such cases it was very difficult to prepare the thin films and to study the conductivity variation with temperature because naphthalene evaporates considerably slowly even at room temperature. 

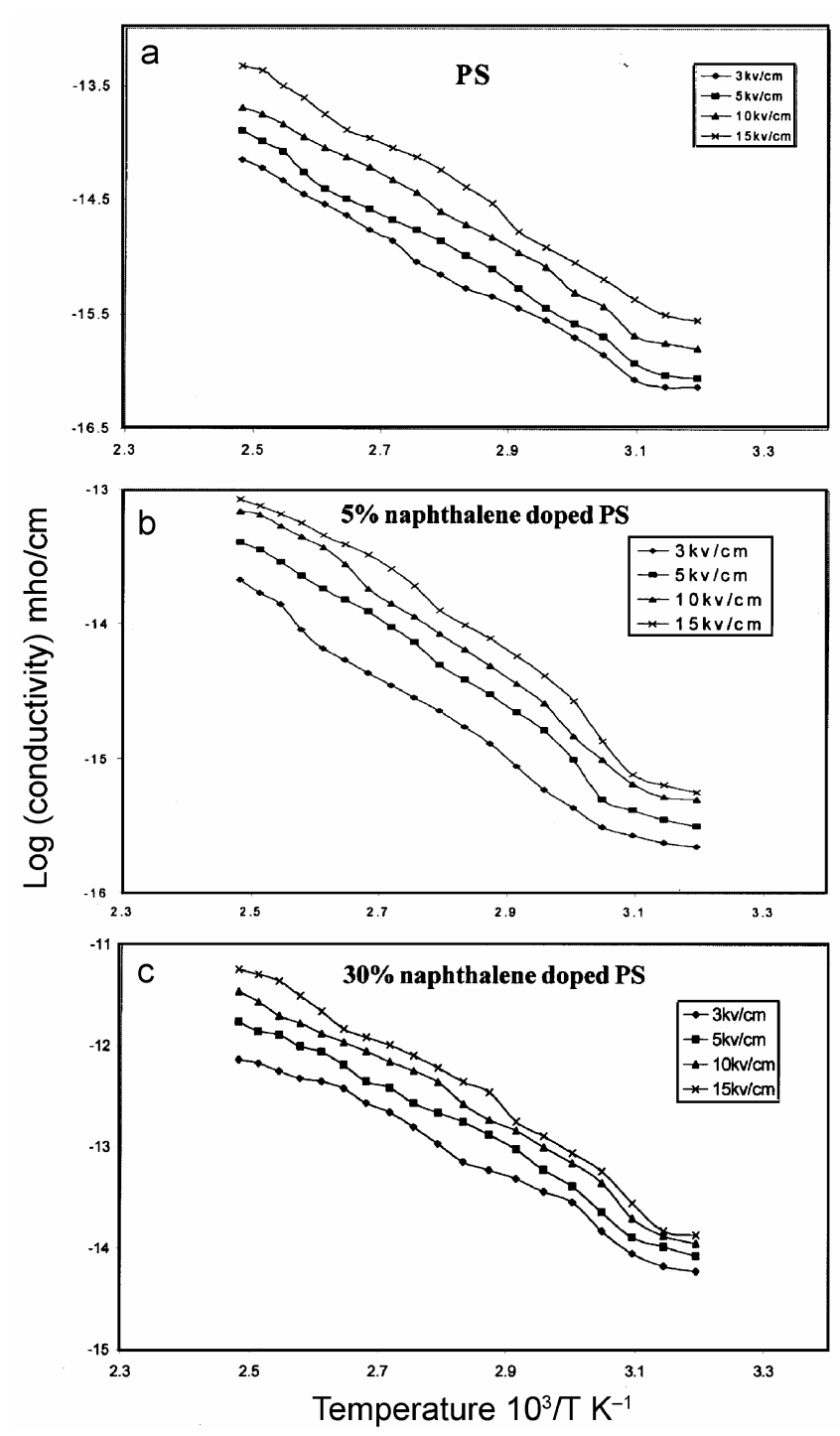

Figure 2. Arrhenius plots of undoped PS and naphthalene doped PS for different polarizing fields: a. undoped PS, b. 5\% naphthalene doped PS and c. 30\% naphthalene doped PS.

Undoped and doped samples are amorphous in nature and it is confirmed by XRD as shown in figure 1 . The conductivity behaviour of such films may be dominated by the properties of amorphous regions (Kosaki et al 1971). Presence of amorphous regions give rise to localized states. Since there are many localized states, the release or excitation of carriers in these states dominates the conduction process. Dopants are present in sufficient quantity and remarkably affect the position of the fermi level. The molecules of dopants enter either in the amorphous regions of the polymer or at the disordered regions like chain folds. If they are present in low concentration they will give rise to additional molecular sites for trapping of charge carriers. Such localized sites formed by dopant molecules can be defined in molecular terms using the difference in ionization potentials as an indication of trap depth. As the dopant concentration is increased, the dopant molecules start bridging the gap separating the two localized states and lowering the potential barrier between them, thereby facilitating the transfer of charge carrier between two localized states. Work reported earlier (Herman and Rembaum 1967; Davies and Lock 1973) suggests the formation of $1: 1$ charge transfer (CT) complex between donor naphthalene and acceptor polystyrene.

Commercially available PS used in the present work is amorphous and the dopant used viz. naphthalene, has an electron donating hydrocarbon group which may act as a trapping centre for charge carriers. The formation of CT complex effectively reduces the trapping effect. A CT complex in the present context means an interaction between two species, the strength of which lies between a full chemical bond and a small orbital overlap. The formation of CT complex between PS and naphthalene at an optimum concentration is evident from the sudden increase in the value of conductivity at higher concentration i.e. $30 \%$ naphthalene of doped samples.

The conductivity of polymer also depends on temperature. As the temperature increases polymer becomes soft and mobility of the main chain segments as well as the rotation of side groups become easier. Thus, at higher temperature more and more dipoles are oriented resulting in the higher equivalent surface charge density i.e. as temperature increases conductivity increases as per Arrhenius equation (Ubale et al 2006),

$$
\sigma=\sigma_{0} \exp \left(-E_{\mathrm{a}} / K T\right)
$$

where $\sigma_{0}$ is the pre-exponential factor, $E_{\mathrm{a}}$ the activation energy of conduction and $K$ the Boltzmann's constant.

The activation energy for these low and high temperature regions are also different as shown in table 1 . The conduction in lower temperature region takes place by thermal activation of carrier from one disordered state to another. At higher temperature, the traps are immobilized because of segmental chain motion or entire chain motion and agrees well with that reported by other workers (Sinha and Srivastava 1979; Tiwari et al 1987).

This could only be explained if we assume that dopant molecules when present in sufficient quantity form a link between trapping centres because of increased orbital overlaps. These experimental findings lead one to understand that steric effects in polymeric CT complex play an important role.

Rembaum et al (1968) suggest that in the polymer system, the acceptor cannot get close to the donor. It seems likely that in many polymeric CT systems, the bulky nature of the groups and their close proximity to the polymer backbone will prevent the maximum interaction and stocking of acceptor layers is characteristic of the highly conducting naphthalene. Steric effects may place a serious limit upon the extent to which conductivity can be enhanced by CT complex formation as evident from the present observations. 
Table 1. Values of activation energies $(\mathrm{eV})$ for undoped and doped polystyrene (PS) at low and high temperature regions.

\begin{tabular}{|c|c|c|c|c|c|c|}
\hline \multirow[b]{2}{*}{ Field $(\mathrm{kV} / \mathrm{cm})$} & \multicolumn{2}{|c|}{ Undoped PSN (0) } & \multicolumn{2}{|c|}{ PSN (5) } & \multicolumn{2}{|c|}{ PSN (30) } \\
\hline & Low $(\mathrm{eV})$ & $\operatorname{High}(\mathrm{eV})$ & Low $(\mathrm{eV})$ & High $(\mathrm{eV})$ & Low $(\mathrm{eV})$ & $\operatorname{High}(\mathrm{eV})$ \\
\hline 3 & $0 \cdot 24$ & $0 \cdot 48$ & $0 \cdot 23$ & $0 \cdot 60$ & $0 \cdot 50$ & $0 \cdot 22$ \\
\hline 5 & 0.423 & $0 \cdot 6$ & $0 \cdot 28$ & $0 \cdot 36$ & 0.59 & $0 \cdot 37$ \\
\hline 10 & $0 \cdot 281$ & $0 \cdot 368$ & $0 \cdot 16$ & $0 \cdot 38$ & $0 \cdot 69$ & $0 \cdot 42$ \\
\hline 15 & $0 \cdot 231$ & $0 \cdot 529$ & $0 \cdot 29$ & $0 \cdot 33$ & $1 \cdot 14$ & $0 \cdot 33$ \\
\hline
\end{tabular}

\section{Conclusions}

The present work shows the combined effect of dopant concentration, polarizing field and temperature on the behaviour of PS. Concentration of dopant increases the conductivity of PS and is increased with polorizing field and temperature.

\section{Acknowledgements}

The authors are thankful to Pune University, Pune, for providing XRD and IR facilities. They also thank Smt S Ghosh, Director, Govt. Vidharbha Institute of Science and Humanities, Amravati, for providing laboratory facilities.

\section{References}

Belsare N G and Deogaonkar V S 1998 Indian J. Pure \& Appl. Phys. 36280

Burghate D K, Deogaonkar V S, Sawarkar S B and Yawale S P 2003 Bull. Mater. Sci. 26267
Chakraborthy S C, Patil N B, Das S K and Basu S 1991 Indian J. Pure \& Appl. Phys. 29478

Davies D K and Lock P J 1973 J. Electrochem. Soc. 120266

Herman A M and Rembaum A 1967 J. Polym. Sci. 17107

Kosaki M, Yoda M and Idea M 1971 J. Phys. Soc. Jap. 31 1598

Mehendru P C and Chand S 1983 Indian J. Pure \& Appl. Phys. 21323

Rembaum A, Hermann A and Haack R 1968 J. Polym. Sci. 6 1955

Ranjit Singh and Datt S C 1980 Indian J. Pure \& Appl. Phys. 18839

Sangawar V S and Adgaonkar C S 1995 Indian J. Pure \& Appl. Phys. 33410

Singh R A, Gupta R K and Singh S K 2005 Bull. Mater. Sci. 28 423

Sinha H C and Srivastava A P 1979 Indian J. Pure \& Appl. Phys. 17726

Tiwari A R, Saraf K K and Shrivastava A P 1987 Electrical and optical behaviour of solid (ed.) R Nath p. 187

Ubale A U, Dhokne R J, Chikhalikar P S, Sangawar V S and Kulkarni D K 2006 Bull. Mater. Sci. 29165 